\title{
CHANGES IN PLANT ATTACK OVER TIME IN NO-CHOICE TESTS: AN INDICATOR OF SPECIFICITY
}

\author{
T.M. WITHERS \\ CRC for Tropical Pest Management, Alan Fletcher Research Station, \\ P.O. Box 36, Q 4075, Brisbane, Australia
}

\begin{abstract}
No-choice testing of insects for extended periods is considered by some weed biological control practitioners to be inappropriate for host range testing due to apparent acceptance of hosts that are not accepted in multiple choice tests. Multiple choice tests can however, produce misleading results if the most stimulating host plant is present in the cage. No-choice tests can yield valuable information on the extent to which food or oviposition site deprivation can induce broadening of host utilisation in the field. Examining the timing of feeding and oviposition in no-choice tests, in conjunction with other assays, is recommended to improve host testing methods.
\end{abstract}

Keywords: host specificity testing, no-choice test, multiple choice test, deprivation

\section{INTRODUCTION}

Predicting the potential impact before release of exotic biocontrol agents on nontarget species is a major issue in biological control. The host testing of proposed agents on a range of economically important species, taxonomically related to the target insect or weed (Wapshere 1974), has been used to determine the range of species acceptable to the agent in the field. In both New Zealand and Australia, biological control practitioners have become very concerned with the possibility that cage testing methods cause insects to attack species that would not be attacked in the field, or to not attack species that would, in fact, be attacked (Cullen 1990). Misleading results can have two consequences; potentially effective and specific insects could be rejected as biocontrol agents, thus causing biocontrol programs to suffer unnecessary costs. Alternatively, the release of exotic agents that may attack non-target native or economically important species has the potential to threaten the future of biocontrol as an acceptable method of weed control.

In the host specificity testing of potential weed biocontrol agents, multiple choice tests in which candidate agents are given access to a number of plant species including the target weed are often favoured, partly because this can be an efficient method of screening several test plants. There is also a perception that host-range as indicated by multiple choice tests, is more closely related to that seen in the field than host-range as indicated by no-choice tests (Blossey 1997; J. Marohasy unpubl.). As well as multiple choice tests, various kinds of no-choice tests are also used. Some assess whether oviposition or feeding occur on test plants, whereas others assess the capacity of the test plant to support pre-adult development and/or reproduction. Some tests examine the outcomes of both processes. Here current methods are reviewed, with particular reference to deprivation-induced increases in responsiveness to plants. A modified procedure for no-choice tests, such that they could be expected to give a more informative indication of field host range, is suggested.

\section{HOST PLANT ACCEPTANCE}

Miller and Strickler (1984) have suggested that a plant is a host when it provides sensory cues such as visual, olfactory, gustatory and tactile cues to which the insect responds positively at each phase of the host finding and acceptance process. Acceptance of the plant 
depends upon the nature of the sensory input elicited from appropriate receptors at each relevant stage in this host finding process. The complex patterns created by positive and negative sensory inputs that produce behavioural responses are the result of neural integration which probably occurs within decision-making centres in the higher central nervous system (CNS). Each plant contacted will induce a certain level of excitation, and in that way can be assigned a rank order of preference to an insect, but the level of excitation will be dependent upon factors influencing the plant such as seasonal effects, plant quality and induced plant defences.

Of particular relevance to the design of host specificity tests is how the internal state of the insect affects its behavioural responses to potential host plants. Behaviour will change with an insects physiological condition (such as nutritional state, oocyte dynamics, age and stage of development; Barton Browne 1993; 1995). We need to understand how physiology, and hence behaviour, is affected by deprivation from oviposition sites or food, as can occur in no-choice tests when the test-plant is less stimulatory to oviposition or feeding than the target weed. Food deprivation causes changes in peripheral receptor sensitivity (Abisgold and Simpson 1988), and probably also in the CNS. Current understanding suggests that these time-related changes in the peripheral receptors and/ or CNS, reduce the threshold of stimulation needed to elicit the behaviour (Barton Browne 1993). This results in deprived insects showing increased behavioural responsiveness towards stimuli associated with potential food or oviposition sites (Papaj and Rausher 1983).

\section{MULTIPLE CHOICE TESTS THAT INCLUDE THE TARGET WEED}

Insects that have recently fed or oviposited have a higher threshold for host acceptance and are less likely to respond to plants (Miller and Strickler 1984). As the threshold lowers, the most stimulating host is usually the first to be accepted (Papaj and Rausher 1983; Singer 1982). Therefore, in choice tests with the target weed present, some insects may remain discriminating throughout the test, and essentially only accept their preferred hosts (J. Marohasy unpubl. data). In some circumstances choice tests may become more stringent, such as when a resource of the preferred host is finite and its quality drops below that of lower ranked hosts present, as a result of host marking or damage (e.g. Heard and Forno 1996). In the field, biocontrol agents can become deprived when the quality or density of the preferred host drops seasonally or from rapid herbivory, and deprived insects may then respond positively to plants that in multiple choice tests are not attacked. For example, the chrysomelid biocontrol agentZygogramma bicolorata (Dejean) fed on sunflower leaves (Helianthus annuиs L.) after defoliating adjacent stands of the host weed Parthenium hysterophorus L. in India (Jayanth et al. 1993), however feeding does not occur on sunflower when it is present in choice tests with $P$. hysterophorus (T. Withers unpubl. data). Choice tests are therefore useful for confirming that the target weed is the most preferred host plant, but do not ascertain the relative acceptability of other hosts. Hence I shall now focus more closely on no-choice tests.

\section{NO-CHOICE TESTS AND DEPRIVATION-INDUCED BROADENING OF HOST RANGE}

Confining insects with lower ranked hosts induces deprivation, to which different insects will respond in different ways. There may be no significant acceptance of lower ranked hosts -classified as 'absolute discrimination'- a desirable trait in biocontrol agents. For example,Bactrocera cacuminatus(Hering)(Tephritidae) will rarely lay eggs on fruit other than that of its preferred host Solanum mauritianum (Scop.), even after 16 days of deprivation (Fitt 1986). However this example can be contrasted to that of the closely related polyphagousBactrocera tryoni (Frogg.) which lays eggs on a wide range of fruit hosts, under a range of deprivation treatments (Fitt 1986).

Deprivation can induce some insects to accept a plant it may reject if not deprived, and this is important for a realistic assessment of the host range of a biocontrol agent. When nochoice oviposition and feeding trials are run for a period of time unmonitored, we cannot ascertain the timing of plant acceptance. Experimentally, deprivation induced acceptance may be ascertained by observing the time from emergence, mating, or from introduction to 
the cage, to when the insect first accepts the plant. An example of deprivation inducing acceptance significantly later in the lifespan of the insect is seen in the AnthomyiidDelia antiqua (Meigen) (Weston et al. 1992). When subject to no-choice tests with artificial 'plants' varying in stimulatory properties, those held with 'plants' lacking chemical stimuli oviposited at a mean 10 days of age, significantly later than those held with chemically treated, artificial 'host plants' which began ovipositing at 7.5 days of age $(\mathrm{P}<0.001$; from Westonet al. 1992). In addition to expressing acceptance behaviour later in the foraging phase, some insects may also lay a lower total number of eggs and/or consume less food of the test plant. For example, females of the short-lived CecidomyiidMayetiola destructor (Say) when held in no-choice tests with host plants, laid four times the number of eggs in total than in no-choice tests with non-host plants. In addition, most eggs were laid between 1200 and 1300 hours on hosts, but when held with non-host plants the eggs were not laid until significantly later, between 1300 - 1500 hours ( $\mathrm{P}<0.05$; from Harris and Rose 1989).

To confirm the role of deprivation in inducing plant acceptance in no-choice tests, groups of insects can be deprived for different periods of time and then placed on test and target plants. If the proportion accepting the test plant is close to zero when not deprived, but increases with increasing deprivation, then not only can we conclude that deprivation is partially responsible for the acceptance, but we get an indication of the circumstances under which this insect may utilise this plant in the field. For example, very few not deprived adult $Z$. bicolorata will feed on the plant Xanthium occidentale Bertol (same sub-tribe as the host plant). However when groups of adult beetles have been deprived of food (but not water) for between 2 and 4 days, $33 \%$ of adult beetles when introduced to the plant will feed on $X$. occidentale, and after 7 days of deprivation, this increases to $72 \%\left(\mathrm{Chi}^{2}=14.3, \mathrm{P}<0.01\right)$. Furthermore in choice tests, $90 \%$ of non-deprived individuals move to $P$. hysterophorus within 3 hours of introduction (T. Withers unpubl. data). To correlate this result to the field situation, $Z$. bicolorata is found feeding on X. occidentale in central Queensland only when adjacent $P$. hysterophorus hosts have been completely defoliated (R. McFadyen pers. comm.). We can therefore conclude that $X$. occidentale is a lesser preferred host plant to $Z$. bicolorata and feeding only occurs when beetles are deprived.

\section{RECOMMENDATIONS}

No-choice tests can be better utilised to indicate specificity in biocontrol agents (sensu Singer 1982), by a fairly straight forward alteration to present no-choice protocols. Instead of leaving larvae or groups or pairs of adult insects unmonitored in no-choice trials for a significant proportion of their lifespan, the foliage or plants should be changed at regular intervals and damage assessed. This interval needs to reflect the lifespan of the agent, for example, hourly for very short-lived adult insects, daily for insects with an adult lifespan of approximately one week, and perhaps every two to three days for more longlived insects. Patterns of quantified plant damage or oviposition can then be statistically compared to that recorded from the similarly-treated control group on the target weed. A significant difference in time-related as well as quantifiable feeding or oviposition patterns, may suggest deprivation has a role in defining host range. Additional information relevant to environmental impact assessments or applications for release, can be obtained by observing individual insects that have been deprived of all feeding or oviposition sites for increasing intervals. How behaviour is expressed on different plants can also indicate specificity (T. Withers unpubl. data). For example, time from introduction to leaving the plant can be related to the probability of the insect remaining on the plant in the field (e.g. Wan and Harris 1996). Further research is needed however, to clarify these types of relationships.

\section{CONCLUSION}

Complete or partial acceptance of plants by a potential biocontrol agent in no-choice tests does not necessarily reflect a lack of field specificity. In many cases it is possible to show that deprivation induces a broadening of host range. Differences in the timing of plant attack on test plants compared to the target weed may indicate specificity of the agent to the target weed in the field. To predict the circumstances under which agents in 
the field may attack lower ranked plants, the feeding and oviposition behaviour of deprived insects could be incorporated into risk-assessment models in applications to import biocontrol agents (Blossey 1997).

\section{ACKNOWLEDGEMENTS}

Thanks to Lindsay Barton Browne, CSIRO, for helpful comments on this paper, and Jennifer Marohasy and Rachel McFadyen, CRC for Tropical Pest Management, for invaluable discussions.

\section{REFERENCES}

Abisgold, J.D. and Simpson, S.J., 1988. The effect of dietary protein levels and haemolymph composition on the sensitivity of the maxillary palp chemoreceptors of locusts. J. Exp. Biol. 135: 215-229.

Barton Browne, L., 1993. Physiologically induced changes in resource-orientated behavior. Ann. Rev. Entomol. 38: 1-25.

Barton Browne, L., 1995. Ontogenic changes in feeding behavior. Pp. 307-342. In: Regulatory Mechanisms in Insect Feeding. R. F. Chapman and G. de Boer (Eds.); Chapman and Hall, London.

Blossey, B., 1997. Host specificity screening of insect biological control agents as part of an environmental risk assessment. Pp. 84-89.In: Biological Control; Benefits and Risks. H.M.T. Hokkanen and J.M. Lynch (Eds.); Cambridge University Press.

Cullen, J.M., 1990. Current problems in host-specificity screening.VII. Int. Symp. Biol. Cont. Weeds: 27-36.

Fitt, G.P., 1986. The influence of a shortage of hosts on the specificity of oviposition behaviour in species of Dacus (Diptera, Tephritidae). Physiol. Entomol. 11: 133143.

Harris, M.O. and Rose, S., 1989. Temporal changes in the egg-laying behaviour of the Hessian fly. Entomol. Exp. Appl. 53: 17-29.

Heard, T.A. and Forno, I.W., 1996. Host selection and host range of the flower-feeding weevil, Coelcephalapion pigrae, a potential biological control agent of Mimosa pigra. Biol. Cont. 6: 83-96.

Jayanth, K.P., Mohandas, S., Asokan, R. and Ganga Visalakshy, P.N., 1993. Parthenium pollen induced feeding by Zygogramma bicolorata (Coleoptera: Chrysomelidae) on sunflower (Helianthus annuus) (Compositae). J. Entom. Res. 83: 595-598.

Miller, J.R. and Strickler, K.L., 1984. Finding and accepting host plants. Pp. 127-157. In: Chemical Ecology of Insects. W. J. Bell and R. T. Cardé(Eds.); Chapman \& Hall, London.

Papaj,D.R. and Rausher, M.D., 1983. Individual variation in hostlocation by phytophagous insects. Pp. 77-124. In: Herbivorous Insects: Host Seeking Behaviour and Mechanisms. S. Ahmad (Ed.); Academic Press, New York.

Singer, M.C., 1982. Quantification of host preference by manipulation of oviposition behaviour in the butterfly Euphydryas editha. Oecologia 52: 224-229.

Wan, F.H. and Harris, P., 1996. Host finding and recognition by Altica carduorum, a defoliator of Cirsium arvense. Entomol. Exp. Appl. 80: 491-496.

Wapshere, A.J., 1974. A strategy for evaluating the safety of organisms for biological weed control. Ann. Appl. Biol. 77: 201-211.

Weston, P.A., Keller, J.E. and Miller, J.R., 1992. Ovipositional stimulus deprivation and its effect on lifetime fecundity ofDelia antiqua(Meigen)(Diptera: Anthomyiidae). Environ. Entomol. 21: 560-565. 